\title{
Quality of life of patients with locally advanced head and neck cancer treated with induction chemotherapy followed by cisplatin-containing chemoradiotherapy in the Dutch CONDOR study: a randomized controlled trial
}

\author{
Chantal M. L. Driessen ${ }^{1}$ • Johannes M. M. Groenewoud ${ }^{2}$. Jan Paul de Boer ${ }^{3}$ • \\ Hans Gelderblom ${ }^{4}$. Winette T. A. van der Graaf ${ }^{1,5}$ • Judith B. Prins ${ }^{6}$ • \\ Johannes H. A. M. Kaanders ${ }^{7}$ - Carla M. L. van Herpen ${ }^{1}$
}

Received: 17 February 2017 / Accepted: 23 October 2017 /Published online: 11 December 2017

(C) The Author(s) 2017. This article is an open access publication

\begin{abstract}
Purpose The CONDOR study showed that docetaxel/cisplatin/5-fluorouracil (TPF) followed by conventional radiotherapy with cisplatin $100 \mathrm{mg} / \mathrm{m}^{2}$ on days 1,22 , and 43 (cis100+ $\mathrm{RT} ; n=27)$ ) versus accelerated radiotherapy with cisplatin weekly $40 \mathrm{mg} / \mathrm{m}^{2}$ (cis40 + ART; $\left.n=29\right)$ in locally advanced head and neck cancer (LAHNC) patients was not feasible. Here, we report the analysis of health-related quality of life (HRQOL) of the patients entered in this study.

Methods HRQOL was assessed at baseline, after two TPF, before start of chemoradiotherapy, and 1, 4, 8, 12, and

Electronic supplementary material The online version of this article (https://doi.org/10.1007/s00520-017-3946-7) contains supplementary material, which is available to authorized users.
\end{abstract}

Carla M. L. van Herpen

carla.vanherpen@ radboudumc.nl

1 Department of Medical Oncology, Radboud University Medical Center, 452, PO Box 9101, 6500 HB Nijmegen, The Netherlands

2 Department of Health Evidence, Radboud University Medical Center, 133, PO Box 9101, 6500 HB Nijmegen, The Netherlands

3 Department of Medical Oncology, Netherlands Cancer Institute-Antoni van Leeuwenhoek Hospital, PO Box 90203, 1006 BE Amsterdam, The Netherlands

4 Department of Medical Oncology, Leiden University Medical Centre, PO Box 9600, 2300 RC Leiden, The Netherlands

5 The institute of Cancer Research and the Royal Marsden NHS Foundation Trust, London, UK

6 Department of Medical Psychology, Radboud University Medical Center, 840, PO Box 9101, 6500 HB Nijmegen, The Netherlands

7 Department of Radiation Oncology, Radboud University Medical Center, 874, PO Box 9101, 6500 HB Nijmegen, The Netherlands
24 months after completion of chemoradiotherapy using the EORTC-QLQ-C30 and QLQ-H\&N35 in 62 patients.

Results Compliance with the QOL questionnaires was $94 \%$ $(59 / 62)$ at baseline and $61 \%(30 / 49)$ at 12 months, respectively. HRQOL decreased after TPF and further decreased during chemoradiohteray in both arms equally. Pain and swallowing dysfunction improved significantly during TPF but deteriorated below baseline levels during chemoradiotherapy, cis40 + ART $>$ cis $100+$ RT $(p<0.05)$. HRQOL and symptoms restored to baseline within 12 months in both arms and remained at that level until 24 months.

Conclusions After TPF, cis40 + ART had a larger negative impact on symptoms than cis $100+$ RT, probably due to the ART. HRQOL and symptoms restored to baseline levels within 12 months after end of treatment in both arms, which is an important perspective for patients during the phase of most serious acute side effects of treatment.

Trial registration: NCT00774319.

Keywords Quality of life · Symptoms · Locally advanced head and neck cancer · Induction chemotherapy ·

Chemoradiotherapy

\section{Introduction}

In patients with locally advanced head and neck cancer (LAHNC), both disease and treatment have a great impact on quality of life (QOL). Standard treatment for these patients is concomitant chemoradiotherapy, which induces severe acute and late toxicities. Common acute toxicities of chemoradiotherapy include mucositis, dermatitis, dysphagia, ototoxicity, and polyneuropathy. Late toxicity may consist of 
dysphagia sometimes with aspiration, odynophagia, xerostomia, fibrosis, and occasionally osteoradionecrosis [1, 2]. These toxicities negatively influence the QOL.

Induction chemotherapy, using docetaxel/cisplatin/5-fluorouracil (TPF), has been proposed as a means to improve outcome of patients with locally advanced head and neck cancer. There are only limited data on TPF followed by chemoradiotherapy using cisplatin. Although it is often stated that neo-adjuvant TPF is well tolerated, the effect of the total regimen, including the concomitant chemoradiation part, on health-related quality of life (HRQOL) has not been reported previously $[3,4]$. HRQOL comprises physical and psychosocial functioning, social interaction and disease- and treatmentrelated symptoms. HRQOL was studied in LAHNC patients receiving neo-adjuvant TPF versus $\mathrm{PF}$ followed by radiotherapy alone, showing a trend towards a better HRQOL during treatment in favor of TPF [5]. Other studies in LAHNC patients treated with chemotherapy and radiotherapy showed a pattern of decline of QOL and then return to baseline within 12 months after end of treatment $[6,7]$. There are no published data of QOL in LAHNC patients treated with induction chemotherapy later than 12 months after end of treatment.

We conducted a randomized phase II feasibility study, the CONDOR study, on induction chemotherapy with TPF followed by cisplatin-based concomitant chemoradiotherapy in two different schedules [8]. Sixty-two fit LAHNC patients started treatment with TPF. Of these patients, 56 were randomized to treatment with concomitant chemoradiotherapy with conventional chemoradiotherapy and cisplatin $100 \mathrm{mg} / \mathrm{m}^{2}$ three weekly (cis100 + RT) (27 patients) or concomitant CRT with accelerated radiotherapy with weekly cisplatin $40 \mathrm{mg} / \mathrm{m}^{2}$ (cis40 + ART) (29 patients). Ninety-six percent of the patients treated with cis $100+\mathrm{RT}$ and $90 \%$ of the patients treated with cis $40+$ ART experienced grade 3 toxicity (on the Common Toxicity Criteria 3.0), whereas grade 4 toxicity occurred in 15 versus $14 \%$ of the patients. Most common grades 3-4 toxicity during TPF was febrile neutropenia (18\%). During concomitant CRT, grades 3-4 toxicities were mucositis in 22 versus $57 \%$, dysphagia in 26 versus $24 \%$, and dehydration in 26 versus $14 \%$, of patients with cis $100+\mathrm{RT}$ and cis 40 + ART, respectively. Both treatment schedules were proven not to be feasible, since the total planned dosage of cisplatin during the chemoradiotherapy could only be administered in $32 \%$ of all patients due to severe toxicity, leading to early termination of inclusion into the study. Despite high toxicity rates, efficacy was comparable with other studies using induction chemotherapy. Response rate after TPF was $61 \%$, and 2 -year overall survival was $77 \%$ in patients treated with cis $100+$ RT and $76 \%$ for those treated with cis $40+$ ART.

In this paper, we will focus on the HRQOL of patients treated in this phase II study with TPF induction chemotherapy followed by concomitant chemoradiotherapy, with emphasis on long-term follow-up outcome.

\section{Methods}

\section{Trial design and participants}

The CONDOR study was a randomized phase II feasibility study on induction chemotherapy with TPF followed by cisplatin-based concomitant chemoradiotherapy in two different schedules. In this study, fit LAHNC patients, stage III or IV with a WHO-performance score of $0-1$ and age $\leq 65$ years, were included. Patients were between 18 and 65 years of age, and adequate bone marrow, hepatic, and renal functions. Exclusion criteria were active alcohol addiction, admission for chronic obstructive pulmonary disease during the last 12 months, and weight loss of more than $10 \%$ during the last 3 months prior to study entry. Details on therapy schedules and toxicity registration and grading were published recently [8].

\section{QOL assessment}

QOL data were collected using the European Organization for Research and Treatment of Cancer (EORTC) QOL questionnaire (QLQ-C30) version 3.0 and the EORTC head and neck cancer module (HN-35) [2, 5, 9-11]. The EORTC QLQ-C30 contains a global HRQOL score, five functional scales (physical, role, cognitive, emotional, and social), three symptom scales (fatigue, nausea/vomiting, and pain), and six singleitem scales (dyspnea, sleep disturbance, appetite loss, constipation, diarrhea, and financial difficulties). The EORTC Head and Neck module, the EORTC QLQ-H\&N35 has been specifically designed and validated for head and neck cancer patients [11]. This is a 35-item questionnaire with seven symptom scales (pain, swallowing, senses, speech, social eating, social contact, and sexuality), six single-item scales (difficulties of teeth, mouth opening, dry mouth, sticky saliva, coughing, and feeling ill), and five items about the additional use of painkillers, nutritional supplements, and feeding tube and changes in body weight. All items were transformed to scales from 0 to 100 , according to the EORTC scoring manual recommendations [12]. A high score on functional scale represents a better level of functioning, whereas a high score on a symptom scale indicates more severe symptoms. Differences of at least 10 points (on a scale of $0-100$ ) on a mean value of the HRQOL parameter were classified as clinically significant [13]. Changes of $\geq 10$ points are moderate, whereas changes of $\geq 20$ points on a mean score are classified as large. The primary HRQOL analysis was based on preselected HRQOL scores: global HRQOL, pain, swallowing, speech, and coughing.

Patients completed the QOL questionnaires at baseline, after 2 cycles of TPF, before start of concomitant chemoradiotherapy (i.e., after 2, 3, or 4 TPF cycles) and 1, 4, 8, 12, 18, and 24 months after the end of chemoradiotherapy. 


\section{Statistical analysis}

HRQOL was a secondary endpoint of the CONDOR study; power analysis was calculated on the primary endpoint, which was feasible. Analyses were performed using SAS version 9.2 and SPSS version 20. Compliance rates were calculated as the number of forms received divided by the number of forms expected at each time point. Expected forms were from patients still alive at the given time point, regardless of disease state. Fishers' exact test was used to determine differences in compliance between the treatment arms. One-sided $t$ test was used to compare the baseline quality-of-life results of the current study with the EORTC reference values.

For the primary analyses, we used an Unstructured Covariance Model to conduct separate repeated measures analyses for each HRQOL outcome [14]. We included time, treatment, and the interaction between time and treatment as fixed factors in the linear mixed model. Time was treated as a categorical variable to allow the model to fit every possible pattern in time. The interaction between time and treatment was only defined after the start of the chemoradiotherapy. In addition, we added the baseline values of the dependent variables as possible significant covariates to the model. Residual plots from the mixed models were examined to assess model assumptions. All linear mixed model analyses were performed on all participants, including those with incomplete datasets. Differences between treatments at specific time moments were estimated from the mixed model. Two-tailed analyses were performed with a $p$ value of 0.05 .
Moreover, sensitivity analysis using the proportion of patients experiencing an improvement/worsening of more than 10 or 20 points in each selected scale was performed [13].

\section{Results}

\section{Participants}

Patient characteristics are shown in Table 1. A CONSORT diagram is added as eFig. 1.

\section{QOL: compliance}

Data of all patients were included in this analysis. Compliance to the questionnaires was $94 \%$ at baseline, $71 \%$ after $2 \mathrm{TPF}$, $70 \%$ before start of chemoradiotherapy, $61 \%$ after chemoradiotherapy, 63\% after 4 months, $66 \%$ after 12 months, $68 \%$ after 18 months, and $62 \%$ after 24 months of follow-up. Compliance was significantly lower in patients treated with cis $40+$ ART at 4 months after end of treatment, 45 versus $81 \%$, respectively $(p=0.006)$. At all other time points compliance between the two treatment arms was similar.

\section{QOL baseline scores}

Baseline QOL scores were compared with the reference values of head and neck cancer patients, stage III-IV diseases (eTable 1), provided by the EORTC [15]. All EORTC head

Table 1 Patient characteristics

\begin{tabular}{|c|c|c|c|}
\hline & $\begin{array}{l}\text { Total }=62 \mathrm{pts} \\
N(\%)\end{array}$ & $\begin{array}{l}\text { Cis } 100+\mathrm{RT}=27 \mathrm{pts} \\
N(\%)\end{array}$ & $\begin{array}{l}\mathrm{Cis} 40+\mathrm{ART}=29 \mathrm{pts} \\
N(\%)\end{array}$ \\
\hline \multicolumn{4}{|l|}{ Sex } \\
\hline Male & $50(80.6)$ & $17(63)$ & $27(93.1)$ \\
\hline Female & $12(19.4)$ & $10(37)$ & $2(6.9)$ \\
\hline \multicolumn{4}{|l|}{ Age (years) } \\
\hline Mean & 53.4 & 54.0 & 53.2 \\
\hline Range & $27-65$ & $32-65$ & $27-64$ \\
\hline \multicolumn{4}{|c|}{ WHO performance status } \\
\hline 0 & $49(79)$ & $23(85.2)$ & $23(79.3)$ \\
\hline 1 & $13(21)$ & $4(14.8)$ & $6(20.7)$ \\
\hline \multicolumn{4}{|l|}{ Tumor site } \\
\hline Oral cavity & $12(19.4)$ & $4(14.8)$ & $6(20.7)$ \\
\hline Oropharynx & $37(59.7)$ & $18(66.7)$ & $16(55.2)$ \\
\hline Hypopharynx & $8(12.9)$ & $3(11.1)$ & $5(17.2)$ \\
\hline Larynx & $5(8.1)$ & $2(7.4)$ & $2(6.9)$ \\
\hline \multicolumn{4}{|l|}{ Disease stage } \\
\hline III & $5(8.1)$ & $2(7.4)$ & $3(10.3)$ \\
\hline IV & 57 (91.9) & 25 (92.6) & 26 (89.7) \\
\hline
\end{tabular}

Abbreviations: pts, patients; Cis $100+\mathrm{RT}$, cisplatinum $100 \mathrm{mg} / \mathrm{m}^{2}$ with conventional radiotherapy; Cis 40 + ART, cisplatinum $40 \mathrm{mg} / \mathrm{m}^{2}$ with accelerated radiotherapy 
Table 2 Mean scores over time at baseline, after two TPF, after chemoradiotherapy

\begin{tabular}{|c|c|c|c|c|c|c|c|c|c|}
\hline & \multicolumn{2}{|c|}{$\begin{array}{l}\text { Baseline (59/ } \\
62)\end{array}$} & \multicolumn{2}{|c|}{$\begin{array}{l}\text { After } 2 \text { TPF (42/ } \\
59)\end{array}$} & \multicolumn{2}{|c|}{$\begin{array}{l}\text { After CRT cis } 100 \text { + RT (18/ } \\
\text { 27) }\end{array}$} & \multicolumn{2}{|c|}{$\begin{array}{l}\text { After CRT cis } 40 \text { + ART (16/ } \\
\text { 29) }\end{array}$} & \multirow[t]{2}{*}{$\begin{array}{l}\text { Difference between } \\
\text { groups CRT ( } p \text { value) }\end{array}$} \\
\hline & Mean & $\mathrm{SD}$ & Mean & SD & Mean & SD & Mean & SD & \\
\hline \multicolumn{10}{|l|}{ EORTC QLQ-30 } \\
\hline Global health status & 75.3 & 19.7 & 70.1 & 11.5 & 44.9 & 11.9 & 46.1 & 12.0 & 0.85 \\
\hline Physical function & 92.0 & 15.1 & $80.5^{\mathrm{a}}$ & 11.2 & 61.0 & 11.5 & 58.4 & 11.6 & 0.60 \\
\hline Role function & 86.1 & 23.8 & $59.6^{\mathrm{a}}$ & 15.2 & 45.0 & 15.9 & 36.0 & 16.2 & 0.32 \\
\hline Emotional function & 74.7 & 21.4 & $84.9^{\mathrm{a}}$ & 12.3 & 84.9 & 12.3 & 77.6 & 12.8 & 0.61 \\
\hline Cognitive function & 91.7 & 15.2 & 87.6 & 18.0 & 70.2 & 18.2 & 67.4 & 18.3 & 0.61 \\
\hline Social function & 87.5 & 18.1 & 79.6 & 14.5 & 66.4 & 14.9 & 67.1 & 15.1 & 0.91 \\
\hline Fatigue & 20.8 & 20.9 & $35.7^{\mathrm{a}}$ & 10.6 & 50.6 & 11.2 & 60.8 & 11.5 & $0.97^{\mathrm{b}}$ \\
\hline Nausea/vomiting & 2.5 & 8.6 & 8.6 & 5.4 & 30.9 & 6.0 & 37.6 & 6.3 & 0.20 \\
\hline Pain & 25.6 & 29.7 & $11.0^{\mathrm{a}}$ & 14.6 & 33.8 & 15.0 & 49.2 & 15.3 & $0.043^{\mathrm{b}}$ \\
\hline Dyspnoea & 6.7 & 14.7 & 9.0 & 11.2 & 16.0 & 11.4 & 19.9 & 11.6 & 0.45 \\
\hline Insomnia & 25.0 & 27.9 & 18.1 & 11.6 & 27.6 & 12.1 & 27.5 & 12.3 & 0.99 \\
\hline Appetite loss & 17.2 & 27.8 & 22.8 & 17.5 & 50.2 & 18.1 & 62.2 & 18.3 & $0.19^{\mathrm{b}}$ \\
\hline Constipation & 12.2 & 24.5 & 11.4 & 5.6 & 20.6 & 6.5 & 32.0 & 6.9 & $0.08^{\mathrm{b}}$ \\
\hline Diarrhea & 2.2 & 8.4 & $12.9^{\mathrm{a}}$ & 8.8 & 8.1 & 9.1 & 10.5 & 9.3 & 0.63 \\
\hline Financial problems & 13.3 & 26.2 & 11.4 & 16.9 & 8.3 & 17.2 & 25.0 & 17.3 & $0.011^{\mathrm{b}}$ \\
\hline \multicolumn{10}{|l|}{ EORTC QLQ-H\&N 35} \\
\hline Pain & 27.2 & 22.5 & $14.5^{\mathrm{a}}$ & 11.9 & 38.1 & 12.2 & 55.7 & 12.3 & $0.003^{\mathrm{b}}$ \\
\hline Swallowing & 24.9 & 25.1 & $9.7^{\mathrm{a}}$ & 10.8 & 43.3 & 11.3 & 59.9 & 11.4 & $0.0101^{\mathrm{b}}$ \\
\hline Senses & 10.5 & 21.0 & $21.7^{\mathrm{a}}$ & 15.2 & 45.0 & 15.6 & 47.3 & 15.8 & 0.74 \\
\hline Speech & 18.1 & 21.3 & 10.9 & 7.9 & 27.1 & 8.5 & 44.8 & 8.7 & $0.004^{\mathrm{b}}$ \\
\hline Social eating & 21.9 & 26.0 & 15.3 & 14.3 & 41.4 & 14.6 & 39.9 & 14.8 & 0.82 \\
\hline Social contact & 5.6 & 14.9 & 7.9 & 6.8 & 12.9 & 7.0 & 9.5 & 7.0 & 0.29 \\
\hline Sexuality & 14.2 & 25.2 & $33.3^{\mathrm{a}}$ & 19.4 & 53.9 & 20.0 & 55.0 & 20.1 & 0.90 \\
\hline Teeth & 19.1 & 27.2 & $6.3^{\mathrm{a}}$ & 14.1 & 10.4 & 14.5 & 15.2 & 14.9 & 0.53 \\
\hline Opening mouth & 25.4 & 34.1 & $13.3^{\mathrm{a}}$ & 16.8 & 27.2 & 17.3 & 31.5 & 17.4 & 0.58 \\
\hline Dry mouth & 15.3 & 24.2 & $25.3^{\mathrm{a}}$ & 18.2 & 44.4 & 18.7 & 56.8 & 18.9 & $0.14^{\mathrm{b}}$ \\
\hline Sticky saliva & 19.5 & 31.2 & 20.5 & 20.2 & 57.5 & 20.6 & 66.3 & 20.8 & 0.32 \\
\hline Coughing & 18.6 & 25.0 & 14.4 & 12.3 & 31.8 & 12.8 & 45.3 & 13.0 & $0.076^{\mathrm{b}}$ \\
\hline Feeling ill & 12.4 & 21.4 & 19.8 & 26.6 & 48.1 & 32.8 & 47.9 & 32.1 & 0.98 \\
\hline Pain killers & 61.0 & 49.2 & $41.2^{\mathrm{a}}$ & 24.9 & 95.6 & 25.9 & 83.5 & 26.3 & $0.40^{\mathrm{b}}$ \\
\hline Nutritional support & 31.0 & 46.7 & $19.7^{\mathrm{a}}$ & 18.5 & 83.0 & 19.6 & 66.0 & 20.0 & $0.20^{\mathrm{b}}$ \\
\hline Feeding tube & 5.1 & 22.2 & 4.8 & 15.7 & 52.3 & 16.6 & 85.0 & 17.0 & $0.003^{\mathrm{b}}$ \\
\hline Weight loss & 43.9 & 50.0 & $15.2^{\mathrm{a}}$ & 14.6 & 81.3 & 16.1 & 33.3 & 17.1 & $0.0009^{\mathrm{b}}$ \\
\hline Weight gain & 17.9 & 38.6 & $50.8^{\mathrm{a}}$ & 21.8 & 26.3 & 23.4 & 19.3 & 24.6 & 0.70 \\
\hline
\end{tabular}

Abbreviations: cis $100+\mathrm{RT}$, cisplatin $100 \mathrm{mg} / \mathrm{m}^{2}$ on days 1,22 , and 43 in combination with conventional radiotherapy; cis $40+\mathrm{ART}, \mathrm{cisplatin} 40 \mathrm{mg} / \mathrm{m}^{2}$ weekly in combination with accelerated radiotherapy; EORTC, European Organization for Research and Treatment of Cancer; QLQ-C30, Quality of Life Questionnaire C30; QLQ-HN-35, Head and Neck Cancer-Specific Module

${ }^{\text {a }}$ Clinically significant difference (10 points or more) after 2 TPF compared to baseline

${ }^{\mathrm{b}}$ Clinically significant difference (10 points or more) between treatment arms after CRT

and neck reference data are based on pretreatment HRQOL. A clinically and statistically significant difference in baseline scores of our patients compared with the EORTC reference values was found on global HRQOL (75.3 versus 63.3, $p<0.001)$ and physical function $(92.0$ versus 81.2 , $p<0.001)$, and on the symptom scores sexuality (14.2 versus $32.2, p<0.001)$, dry mouth (15.3 versus $31.1, p<0.001)$, sticky saliva 19.5 versus $32.4, p<0.001)$, coughing $(18.6$ versus $34.9, p<0.001)$, feeling ill $(12.4$ versus 21.7 , $p=0.003)$, and feeding tube (5.1 versus $18.3, p<0.001)$, in 


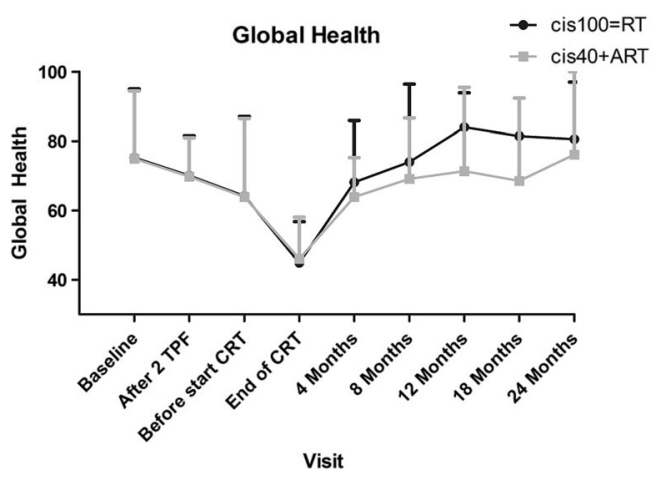

Fig. 1 Mean Global Health Scores over time by treatment arm

favor of the patients in our study. This indicates that in terms of QOL a relatively favorable (i.e., fit) patient group was selected for this study.

\section{QOL during TPF}

Global HRQOL decreased non-significantly after 2 TPF (70.1) and even more after the end of TPF (64.0) (Table 2; Fig. 1). Pain and swallowing problems both decreased with more than 10 points after 2 TPF, but both increased before start of chemoradiotherapy (Table 2; Fig. 2). Speech problems and coughing improved nonsignificantly after two TPF, but deteriorated at the end of TPF (Table 2; Fig. 2).

\section{QOL: differences between treatment arms during chemoradiotherapy and changes over time}

Global HRQOL decreased during chemoradiotherapy, equally in both arms (Table 2; Fig. 1). Four months after end of treatment, global HRQOL increased and it was restored to baseline levels within 12 months after end of treatment. Beyond 12 months however, patients treated with cis $100+$ RT had a higher score than the patients treated with cis40 + ART, albeit not significant. Twentyfour months after end of treatment global HRQOL was equal in both arms (Table 3). Pain, swallowing problems, speech problems and coughing all worsened during chemoradiotherapy. A clinically and statistically significant difference between the treatment arms at end of treatment was found in all these symptom scores in favor of the patients treated with cis $100+$ RT (Table 2; Fig. 2). In both treatment arms, pain, swallowing problems, and speech problems recovered to baseline level 4 months after treatment. There were no differences in mean scores of pain, swallowing problems, speech problems, and coughing between the treatment arms at 12 and 24 months after end of treatment (Table 3).

\section{Other HRQOL scales}

All other HRQOL items were analyzed on an exploratory basis. Patients treated with cis40 + ART scored clinically and statistically significantly worse on feeding tube dependence after CRT but significantly better on nutritional support and use of painkillers. Patients treated with cis $100+$ RT scored clinically and statistically significant worse on weight loss.

Moreover, a clinically significant difference ( $>10$ points) was found for fatigue, appetite loss, constipation, and dry mouth in favor of cis $100+$ RT.

Furthermore, after 2 years follow-up patients treated with cis100 + RT had clinically significant ( $>10$ points) better cognitive function and less sticky saliva compared with patients treated with cis 40 + ART. Patients treated with cis40 + ART scored clinically significant worse on nutritional support and feeding tube than patients in arm cis $100+$ RT (Table 3).

\section{Sensitivity analyses}

The proportion of patients experiencing an improvement or worsening of 10 or 20 points on the selected scales between baseline and end of chemoradiotherapy were compared between the treatment arms. These analyses showed the same trend of more pain in patients treated with cis40 + ART compared with cis $100+$ RT (Table 4). Moreover, a higher percentage of patients experienced a worsening in speech and swallowing problems in the group treated with cis40 + ART, whereas more patients experienced improvement in the group treated with cis $100+$ RT (Table 4).

\section{Discussion}

HRQOL was assessed as secondary endpoint of the randomized phase II CONDOR study in patients with locally advanced head and neck cancer treated with TPF induction chemotherapy followed by cisplatin $100 \mathrm{mg} / \mathrm{m}^{2}$ with conventional radiotherapy versus cisplatin $40 \mathrm{mg} / \mathrm{m}^{2}$ with accelerated radiotherapy. Our study patients had a clinically 

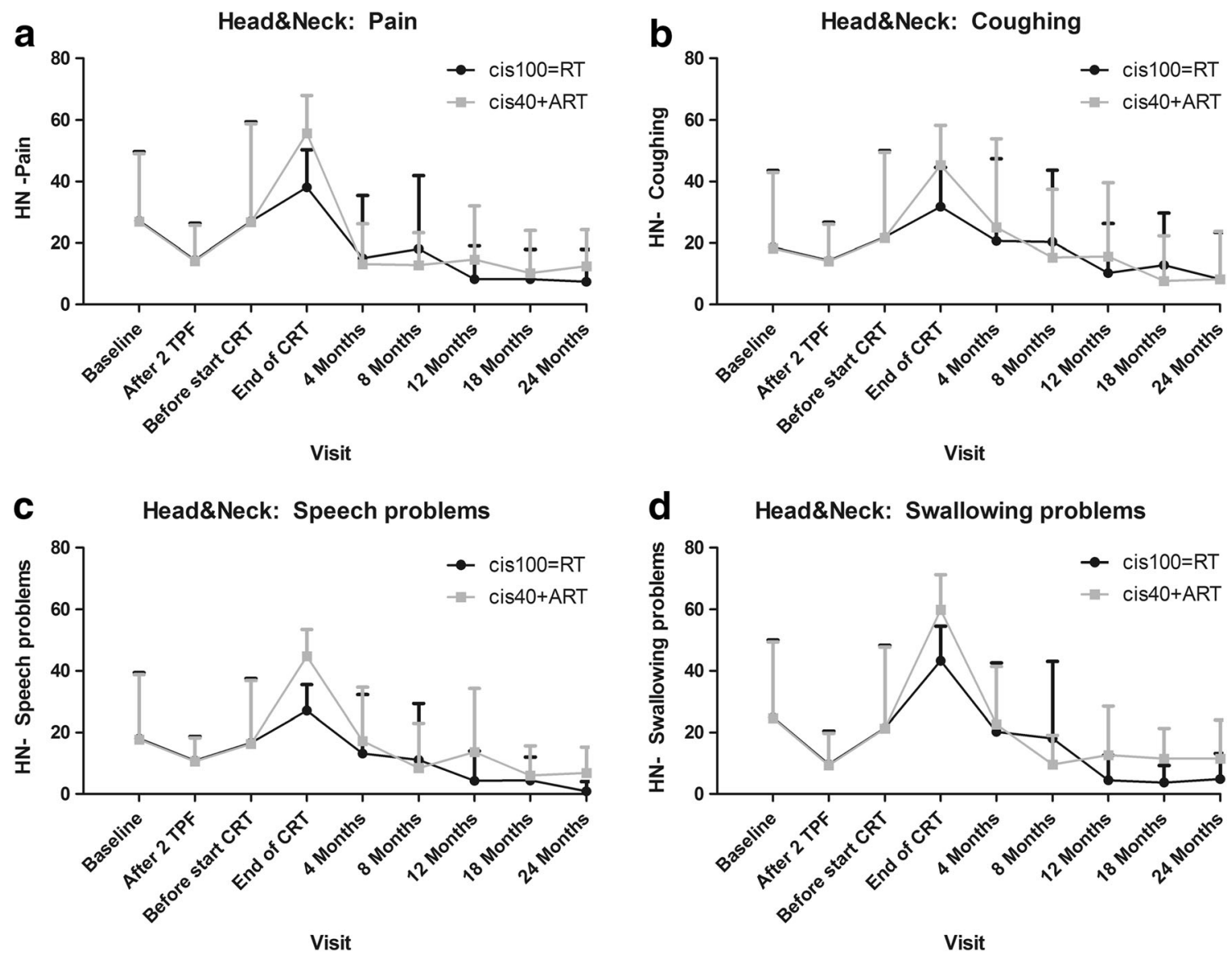

Fig. 2 Mean symptom scores over time by treatment arm: a pain, $\mathbf{b}$ coughing, $\mathbf{c}$ speech problems, and $\mathbf{d}$ swallowing problems

and statistically significant better global HRQOL and physical function compared with the EORTC reference values for head and neck cancer patients with stage III-IV disease, which data were obtained during standard treatment [15]. Global HRQOL in our patients was also better than the patients included in the EORTC 24971/TAX 323 study [5]. This is a reflection of our selection criteria to include only very fit LAHNC patients, i.e., no admissions for COPD in the past year, WHO 0-1, no weight loss more than $10 \%$ in the past 3 months, no active alcohol addiction, and adequate bone marrow, liver, and kidney functions. Despite the excellent clinical condition of our patients at baseline reflected by the good global HRQOL, both treatment schedules were shown not feasible [8].

Global HRQOL declined during TPF and more during chemoradiotherapy, without any difference between the two treatment arms. The declining global HRQOL is in contrast with the results of the EORTC 24971/TAX 323 study, where global HRQOL improved during TPF [5]. In that study however, baseline global HRQOL was significantly lower than in our study $(61.2$ versus 75.3 , respectively, $p<0.001)$. After 2 cycles of TPF though, global HRQOL scores in the CONDOR and TAX 323 cohorts were comparable, 70.1 and 69.3, respectively. However, before start with CRT the global HRQOL scores of the CONDOR cohort decreased further (64.0) while the TAX 323 cohort remained stable $(70.7 ; p<0.05)$. This is in agreement with Tribius et al. who reported a significant greater deterioration in global HRQOL in patients with the highest baseline scores [16].

Global HRQOL restored to baseline levels within 12 months after end of treatment and remained at that level after 24 months. This is in line with other QOL in head and neck cancer studies $[6,9,17]$ and is not very satisfying, because an improvement in Qol is desirable in cured patients. This pattern of no improvement in quality of life could be hypothetically caused by substitution of tumor-associated complaints at presentation by therapy sequelae-associated complaints leading to high symptom scores after the end of treatment [18]. Other studies concerning induction chemotherapy in head and neck cancer did not include QOL analysis [19-21].

In contrast to the declining global HRQOL scores, we found improvement of symptom scores, especially for pain and swallowing problems during TPF. This is in line with the results of the EORTC 24971/TAX 323 study [5] and presumably reflects tumor response, which is consistent with our efficacy results; $62 \%$ of the patients had 
Table 3 Mean scores over time at baseline, and after 1 and 2 years after treatment

\begin{tabular}{|c|c|c|c|c|c|c|c|c|c|c|}
\hline & \multicolumn{2}{|c|}{$\begin{array}{l}\text { 1-year follow-up } \\
\text { cis } 100+\mathrm{RT}\end{array}$} & \multicolumn{2}{|c|}{$\begin{array}{l}\text { 1-year follow-up } \\
\text { cis } 40+\text { ART }\end{array}$} & \multirow[t]{2}{*}{$\begin{array}{l}\text { Difference between } \\
\text { groups ( } p \text { value) }\end{array}$} & \multicolumn{2}{|c|}{$\begin{array}{l}\text { 2-year follow-up } \\
\text { cis } 100+\mathrm{RT}\end{array}$} & \multicolumn{2}{|c|}{$\begin{array}{l}\text { 2-year follow-up } \\
\text { cis } 40+\text { ART }\end{array}$} & \multirow[t]{2}{*}{$\begin{array}{l}\text { Difference between } \\
\text { groups ( } p \text { value) }\end{array}$} \\
\hline & Mean & SD & Mean & SD & & Mean & SD & Mean & SD & \\
\hline \multicolumn{11}{|l|}{ EORTC QLQ-30 } \\
\hline Global health status & 84.0 & 9.9 & 71.4 & 24.1 & $0.07^{\mathrm{a}}$ & 80.6 & 16.4 & 76.2 & 23.8 & 0.64 \\
\hline Physical function & 91.3 & 10.7 & 85.1 & 16.1 & 0.22 & 92.8 & 7.8 & 88.6 & 11.4 & 0.35 \\
\hline Role function & 87.2 & 15.4 & 73.5 & 37.7 & $0.19^{\mathrm{a}}$ & 83.3 & 22.5 & 73.8 & 30.2 & 0.44 \\
\hline Emotional function & 91.0 & 10.5 & 78.6 & 24.9 & $0.09^{\mathrm{a}}$ & 83.3 & 25.1 & 88.1 & 16.6 & 0.66 \\
\hline Cognitive function & 93.6 & 8.4 & 81.3 & 25.7 & $0.09^{\mathrm{a}}$ & 88.9 & 16.4 & 69.0 & 33.9 & $0.19^{\mathrm{b}}$ \\
\hline Social function & 91.0 & 12.9 & 81.3 & 29.7 & 0.28 & 93.1 & 13.2 & 88.1 & 15.9 & 0.47 \\
\hline Fatigue & 16.2 & 17.9 & 23.5 & 24.5 & 0.37 & 22.2 & 21.7 & 28.6 & 31.3 & 0.61 \\
\hline Nausea/vomiting & 0.0 & 0.0 & 3.92 & 11.1 & 0.16 & 0.0 & 0.0 & 7.1 & 18.9 & 0.36 \\
\hline Pain & 5.1 & 10.5 & 16.7 & 30.0 & $0.16^{\mathrm{a}}$ & 8.3 & 16.7 & 7.1 & 18.9 & 0.89 \\
\hline Dyspnoea & 2.6 & 9.2 & 13.7 & 20.6 & $0.08^{\mathrm{a}}$ & 2.8 & 9.6 & 9.5 & 16.3 & 0.35 \\
\hline Insomnia & 2.6 & 9.2 & 17.6 & 20.8 & $0.02^{\mathrm{a}}$ & 11.1 & 21.7 & 14.3 & 17.8 & 0.75 \\
\hline Appetite loss & 7.7 & 20.0 & 17.6 & 26.7 & 0.25 & 5.6 & 13.0 & 14.3 & 26.2 & 0.44 \\
\hline Constipation & 0.0 & 0.0 & 11.8 & 20.2 & $0.046^{\mathrm{a}}$ & 5.6 & 13.0 & 0.0 & 0.0 & 0.17 \\
\hline Diarrhea & 0.0 & 0.0 & 2.1 & 8.3 & 0.33 & 0.0 & 0.0 & 4.8 & 12.6 & 0.36 \\
\hline Financial problems & 10.3 & 16.0 & 14.6 & 29.7 & 0.62 & 0.0 & 0.0 & 4.8 & 12.6 & 0.36 \\
\hline \multicolumn{11}{|l|}{ EORTC QLQ-H\&N 35} \\
\hline Pain & 8.3 & 10.8 & 14.7 & 17.3 & 0.23 & 7.4 & 10.5 & 12.5 & 11.8 & 0.33 \\
\hline Swallowing & 4.5 & 8.1 & 12.7 & 15.9 & 0.08 & 4.9 & 8.3 & 11.5 & 12.5 & 0.17 \\
\hline Senses & 17.9 & 17.3 & 17.6 & 21.6 & 1.00 & 16.7 & 26.6 & 12.5 & 7.7 & 0.62 \\
\hline Speech & 4.3 & 9.7 & 13.7 & 20.6 & 0.11 & 0.9 & 3.2 & 6.9 & 8.3 & 0.08 \\
\hline Social eating & 10.9 & 11.0 & 19.1 & 24.6 & 0.19 & 6.9 & 12.7 & 17.7 & 22.0 & $0.18^{\mathrm{b}}$ \\
\hline Social contact & 0.5 & 1.8 & 7.3 & 14.8 & 0.23 & 0.6 & 1.9 & 1.7 & 4.7 & 0.47 \\
\hline Sexuality & 12.5 & 16.1 & 27.8 & 26.5 & $0.09^{\mathrm{a}}$ & 11.1 & 17.9 & 13.9 & 16.4 & 0.75 \\
\hline Teeth & 2.6 & 9.2 & 14.6 & 27.1 & $0.11^{\mathrm{a}}$ & 5.6 & 13.0 & 8.3 & 23.6 & 0.74 \\
\hline Opening mouth & 12.8 & 16.9 & 15.7 & 20.8 & 0.69 & 13.9 & 22.3 & 20.8 & 24.8 & 0.52 \\
\hline Dry mouth & 43.6 & 21.0 & 49.0 & 29.1 & 0.58 & 33.3 & 24.6 & 41.7 & 23.6 & 0.46 \\
\hline Sticky saliva & 17.9 & 22.0 & 31.3 & 28.5 & $0.18^{\mathrm{a}}$ & 16.7 & 22.5 & 37.5 & 21.4 & $0.05^{\mathrm{b}}$ \\
\hline Coughing & 10.3 & 16.0 & 15.7 & 23.9 & 0.49 & 8.3 & 15.1 & 8.3 & 15.4 & 1.00 \\
\hline Feeling ill & 2.6 & 9.2 & 17.6 & 31.4 & $0.08^{\mathrm{a}}$ & 8.3 & 20.7 & 4.2 & 11.8 & 0.61 \\
\hline Pain killers & 7.7 & 27.7 & 23.5 & 43.7 & $0.24^{\mathrm{a}}$ & 16.7 & 38.9 & 25.0 & 46.3 & 0.67 \\
\hline Nutritional support & 15.4 & 37.6 & 23.5 & 43.7 & 0.60 & 0.0 & 0.0 & 12.5 & 35.4 & $0.35^{\mathrm{b}}$ \\
\hline Feeding tube & 0.0 & 0.0 & 5.9 & 24.3 & 0.39 & 0.0 & 0.0 & 12.5 & 35.4 & $0.35^{\mathrm{b}}$ \\
\hline Weight loss & 0.0 & 0.0 & 25.0 & 44.7 & $0.04^{\mathrm{a}}$ & 8.3 & 28.9 & 12.5 & 35.4 & 0.78 \\
\hline Weight gain & 46.2 & 51.9 & 31.3 & 47.9 & $0.43^{\mathrm{a}}$ & 41.7 & 51.5 & 25.0 & 46.3 & $0.47^{\mathrm{b}}$ \\
\hline
\end{tabular}

Abbreviations: cis $100+\mathrm{RT}$, cisplatin $100 \mathrm{mg} / \mathrm{m}^{2}$ on days 1,22 , and 43 in combination with conventional radiotherapy; cis $40+\mathrm{ART}, \mathrm{cisplatin} 40 \mathrm{mg} / \mathrm{m}^{2}$ weekly in combination with accelerated radiotherapy; EORTC, European Organization for Research and Treatment of Cancer; QLQ-C30, Quality of Life Questionnaire C30; QLQ-HN-35, Head and Neck Cancer-Specific Module

${ }^{a}$ Clinically significant difference (10 points or more) 1 year after treatment between treatment arms

${ }^{\mathrm{b}}$ Clinically significant difference (10 points or more) between treatment arms after 2 years

partial or complete responses after TPF. The improvement in pain and swallowing problems did not lead to better global health. Probably, the increase of other symptom scores such as fatigue, constipation, and feeling ill plays a role in declining global health score.
Patients in the CONDOR study showed differences in physician rated toxicity scores of mucositis and dysphagia between the two treatment arms, showing more grades 3 and 4 mucositis in the patients treated with cis $40+$ ART (59 versus $26 \%)$. The differences in symptom scores on speech 
Table 4 Sensitivity analysis: proportion of patients experiencing improvement/ worsening of selected scales after chemoradiotherapy compared with baseline

\begin{tabular}{|c|c|c|c|}
\hline & $\begin{array}{l}\text { Cis100 + RT }(N=27) \mathrm{N} \\
(\%)\end{array}$ & $\begin{array}{l}\text { Cis } 40+\operatorname{ART}(N=29) \mathrm{N} \\
(\%)\end{array}$ & $\begin{array}{l}p \text { value for } \\
\text { difference }\end{array}$ \\
\hline \multicolumn{4}{|l|}{ Global qualiy of life $^{\mathrm{a}}$} \\
\hline$\geq 16.6$ points worsening & $15(83.3)$ & $10(71.4)$ & 0.669 \\
\hline$\geq 25$ points worsening & $13(72.2)$ & $8(57.1)$ & 0.465 \\
\hline $\begin{array}{l}\geq 16.6 \text { points } \\
\text { improvement }\end{array}$ & $0(0)$ & $1(7.1)$ & 0.437 \\
\hline $\begin{array}{l}\geq 25 \text { points } \\
\text { improvement }\end{array}$ & $0(0)$ & 0 & 1.00 \\
\hline \multicolumn{4}{|l|}{ Coughing $^{\mathrm{b}}$} \\
\hline$\geq 33.3$ points worsening & $10(58.8)$ & $8(57.1)$ & 1.00 \\
\hline $\begin{array}{l}\geq 33.3 \text { points } \\
\text { improvement }\end{array}$ & $3(17.6)$ & $3(21.4)$ & 1.00 \\
\hline \multicolumn{4}{|l|}{ Pain $^{\mathrm{c}}$} \\
\hline$\geq 11.1$ points worsening & $8(47.1)$ & $12(85.7)$ & 0.057 \\
\hline$\geq 22.2$ points worsening & $7(41.2)$ & $11(78.6)$ & 0.067 \\
\hline $\begin{array}{l}\geq 11.1 \text { points } \\
\text { improvement }\end{array}$ & $4(23.5)$ & $2(14.3)$ & 0.664 \\
\hline $\begin{array}{l}\geq 22.2 \text { points } \\
\text { improvement }\end{array}$ & $2(11.8)$ & $1(7.1)$ & 1.00 \\
\hline \multicolumn{4}{|l|}{ Speech problems ${ }^{\mathrm{d}}$} \\
\hline$\geq 11.1$ points worsening & $8(47.1)$ & $10(71.4)$ & 0.275 \\
\hline$\geq 22.2$ points worsening & $6(35.3)$ & $8(57.1)$ & 0.289 \\
\hline $\begin{array}{l}\geq 11.1 \text { points } \\
\text { improvement }\end{array}$ & $5(29.4)$ & $2(14.3)$ & 0.412 \\
\hline $\begin{array}{l}\geq 22.2 \text { points } \\
\text { improvement }\end{array}$ & $4(23.5)$ & $2(14.3)$ & 0.664 \\
\hline \multicolumn{4}{|l|}{ Swallowing $^{\mathrm{e}}$} \\
\hline$\geq 11.1$ points worsening & $12(70.6)$ & $11(78.6)$ & 0.698 \\
\hline$\geq 22.2$ points worsening & $11(64.7)$ & $10(71.4)$ & 1.00 \\
\hline $\begin{array}{l}\geq 11.1 \text { points } \\
\text { improvement }\end{array}$ & $4(23.5)$ & $2(14.3)$ & 0.664 \\
\hline $\begin{array}{l}\geq 22.2 \text { points } \\
\text { improvement }\end{array}$ & $3(17.6)$ & $1(7.1)$ & 0.607 \\
\hline
\end{tabular}

Abbreviations: cis $100+\mathrm{RT}$, cisplatin $100 \mathrm{mg} / \mathrm{m}^{2}$ on days 1,22 , and 43 in combination with conventional radiotherapy; cis 40 + ART, cisplatin $40 \mathrm{mg} / \mathrm{m}^{2}$ weekly in combination with accelerated radiotherapy

${ }^{\text {a }}$ Global QoL score may take all values from 0 to 100 distance by 8.3 points $(0,8.3,16.6$, and so on). A shift of more than 10 points means a shift of 16.6 points or more. A shift of more than 20 points means a shift of 25 points or more

${ }^{\mathrm{b}}$ Coughing score may take all values from 0 to 100 distance by 33.3 points $(0,33.3,66.6$, and so on)

${ }^{\mathrm{c}}$ Pain score may take all values from 0 to 100 distance by 2.8 points

${ }^{\mathrm{d}}$ Speech score may take all values from 0 to 100 distance by 5.5 points

${ }^{\mathrm{e}}$ Swallowing score may take all values from 0 to 100 distance by 2.8 points problems, swallowing problems and pain in favor of the patients treated with cis $100+$ RT are in line with this. As described earlier, the difference in mucositis can be explained by the toxicity caused by accelerated radiotherapy and the weekly radio-sensitizing effect of cisplatin [8, 22]. High toxicity rates were observed with this treatment schedule, causing increasing symptom scores and decreasing global HRQOL during treatment. Despite this, all symptom scores in both treatment arms returned to baseline level at 12 months after end of treatment.
The main limitations of this study are the relatively small patient population and the difference in compliance between the two treatment arms at 4 months after chemoradiotherapy namely $45 \%$ versus $81 \%$ in cis $40+$ ART and cis $100+$ RT respectively. This difference in compliance rate at 4 months could have led to selection bias, since patients treated with cis40 + ART experienced more toxicity during chemoradiotherapy and had worse symptom scores. Assuming that the patients treated with cis $40+$ ART who had more symptoms were less likely to return 
the questionnaires, possibly the QoL scores at 4 months for this group are overestimated.

Our study has several strengths. It has a randomized design, and it is the first study reporting on QOL in patients treated with induction chemotherapy followed by concomitant cisplatin-based chemoradiotherapy. Because we used standard and validated questionnaires, comparison of our results with other studies in locally advanced head and neck cancer is possible. Overall compliance in our study was high, with more than $60 \%$ returned questionnaires during treatment as well as after 1 and 2 years after end of treatment. This is much higher than the compliance rate of $45 \%$ after 9 months in the EORTC 24971/ TAX 323 study [5].

In summary, in our patients with locally advanced head and neck cancer, we found high baseline HRQOL scores. However, despite this initial high global health score, reflecting the good condition of the patients participating in the CONDOR study, both chemoradiation treatment schedules after prior TPF chemotherapy were shown not feasible. Especially patients treated with cis40 + ART experienced high rates of grades 3 and 4 mucositis and consequently high symptom scores (pain, swallowing problems, and feeding tube dependence) during treatment.

Importantly, global health and all the symptom scores restored to baseline levels within 12 months after end of treatment in both arms and remained at that level at 2 years of follow-up after end of treatment. This is remarkable given the impressive toxicity the patients have gone through, and important with regard to the quality of the survivorship of these patients who presented with such advanced localized head and neck carcinomas.

\begin{abstract}
Acknowledgments The authors thank all the patients and their families who participated in our study. Furthermore, we thank all the staff of the participating hospitals and the Dutch Head and Neck Society for supporting this study. Chantal Driessen had full access to all of the data in the study and takes responsibility for the integrity of the data and the accuracy of the data analysis.
\end{abstract}

Authors' contributions Chantal Driessen is responsible for the inclusion of patients, interpretiation of data, writing manuscript, and final approval. Hans Groenewoud is responsible for statistical analysis and interpretation of data, revising manuscript, and final approval. Jan Paul de Boer is responsible for the investigator study, inclusion of patients, revising manuscript, and final approval. Hans Gelderblom is responsible for the inclusion of patients, revising manuscript, and final approval. Winette van der Graaf is responsible for investigator study, revising manuscript, final approval, and overall content. Judith Prins is responsible for interpreting data, revising manuscript, and final approval. Hans Kaanders is responsible for investigator study, study design, inclusion of patients, revising manuscript, and final approval. Carla van Herpen is responsible for principal investigator study, study design, inclusion of patients, revising manuscript, final approval, and overall content.FundingThis work was supported by Sanofi-Aventis Netherlands B.V. and the Dutch Cancer Society [KUN 2008-4328].

\section{Compliance with ethical standards}

Conflict of interest The authors declare that they have no conflict of interest.

Open Access This article is distributed under the terms of the Creative Commons Attribution-NonCommercial 4.0 International License (http:// creativecommons.org/licenses/by-nc/4.0/), which permits any noncommercial use, distribution, and reproduction in any medium, provided you give appropriate credit to the original author(s) and the source, provide a link to the Creative Commons license, and indicate if changes were made.

\section{References}

1. Bentzen SM, Trotti A (2007) Evaluation of early and late toxicities in chemoradiation trials. J Clin Oncol 25:4096-4103

2. Rutten H, Pop LA, Janssens GO, Takes RP, Knuijt S, Rooijakkers $\mathrm{AF}$, van den Berg M, Merkx MA, van Herpen CM, Kaanders JH (2011) Long-term outcome and morbidity after treatment with accelerated radiotherapy and weekly cisplatin for locally advanced head-and-neck cancer: results of a multidisciplinary late morbidity clinic Int J Radiat Oncol Biol Phys 81: 923-929

3. Posner MR, Hershock DM, Blajman CR, Mickiewicz E, Winquist E, Gorbounova V, Tjulandin S, Shin DM, Cullen K, Ervin TJ, Murphy BA, Raez LE, Cohen RB, Spaulding M, Tishler RB, Roth B, Viroglio Rdel C, Venkatesan V, Romanov I, Agarwala S, Harter KW, Dugan M, Cmelak A, Markoe AM, Read PW, Steinbrenner L, Colevas AD, Norris CM Jr, Haddad RI, Group TAXS (2007) Cisplatin and fluorouracil alone or with docetaxel in head and neck cancer. N Engl J Med 357:1705-1715

4. Vermorken JB, Remenar E, van Herpen C, Gorlia T, Mesia R, Degardin M, Stewart JS, Jelic S, Betka J, Preiss JH, van den Weyngaert D, Awada A, Cupissol D, Kienzer HR, Rey A, Desaunois I, Bernier J, Lefebvre JL, Group ETS (2007) Cisplatin, fluorouracil, and docetaxel in unresectable head and neck cancer. $\mathrm{N}$ Engl J Med 357:1695-1704

5. van Herpen CM, Mauer ME, Mesia R, Degardin M, Jelic S, Coens C, Betka J, Bernier J, Remenar E, Stewart JS, Preiss JH, van den Weyngaert D, Bottomley A, Vermorken JB, Head E, Neck G (2010) Short-term health-related quality of life and symptom control with docetaxel, cisplatin, 5-fluorouracil and cisplatin (TPF), 5fluorouracil (PF) for induction in unresectable locoregionally advanced head and neck cancer patients (EORTC 24971/TAX 323). Br J Cancer 103:1173-1181

6. Curran D, Giralt J, Harari PM, Ang KK, Cohen RB, Kies MS, Jassem J, Baselga J, Rowinsky EK, Amellal N, Comte S, Bonner JA (2007) Quality of life in head and neck cancer patients after treatment with high-dose radiotherapy alone or in combination with cetuximab. J Clin Oncol 25:2191-2197

7. Bottomley A, Tridello G, Coens C, Rolland F, Tesselaar ME, Leemans CR, Hupperets P, Licitra L, Vermorken JB, Van Den Weyngaert D, Truc G, Barillot I, Lefebvre JL (2014) An international phase 3 trial in head and neck cancer: quality of life and symptom results: EORTC 24954 on behalf of the EORTC Head and Neck and the EORTC Radiation Oncology Group. Cancer 120: 390-398

8. Driessen CM, de Boer JP, Gelderblom H, Rasch CR, de Jong MA, Verbist BM, Melchers WJ, Tesselaar ME, van der Graaf WT, Kaanders JH, van Herpen CM (2015) Induction chemotherapy with docetaxel/cisplatin/5-fluorouracil followed by randomization to two cisplatin-based concomitant chemoradiotherapy schedules in patients with locally advanced head and neck cancer (CONDOR 
study) (Dutch Head and Neck Society 08-01): a randomized phase II study Eur J Cancer 52: 77-84

9. Rathod S, Gupta T, Ghosh-Laskar S, Murthy V, Budrukkar A, Agarwal J (2013) Quality-of-life (QOL) outcomes in patients with head and neck squamous cell carcinoma (HNSCC) treated with intensity-modulated radiation therapy (IMRT) compared to threedimensional conformal radiotherapy (3D-CRT): evidence from a prospective randomized study. Oral Oncol 49:634-642

10. Bjordal K, de Graeff A, Fayers PM, Hammerlid E, van Pottelsberghe C, Curran D, Ahlner-Elmqvist M, Maher EJ, Meyza JW, Bredart A, Soderholm AL, Arraras JJ, Feine JS, Abendstein H, Morton RP, Pignon T, Huguenin P, Bottomly A, Kaasa S (2000) A 12 country field study of the EORTC QLQ$\mathrm{C} 30$ (version 3.0) and the head and neck cancer specific module (EORTC QLQ-H\&N35) in head and neck patients. EORTC Quality of Life Group. Eur J Cancer 36:1796-1807

11. Bjordal K, Hammerlid E, Ahlner-Elmqvist M, de Graeff A, Boysen M, Evensen JF, Biorklund A, de Leeuw JR, Fayers PM, Jannert M, Westin T, Kaasa S (1999) Quality of life in head and neck cancer patients: validation of the European Organization for Research and Treatment of cancer quality of life questionnaire-H\&N35. J Clin Oncol 17:1008-1019

12. Fayers PM AN, Bjordal K, Groenvold M, Curran D, Bottomley A, on behalf of the EORTC Quality of Life Group. (2001) The EORTC QLQ-C30 scoring manual (3rd edition). European Organisation for Research and Treatment of Cancer, Brussels, Belgium

13. Osoba D, Rodrigues G, Myles J, Zee B, Pater J (1998) Interpreting the significance of changes in health-related quality-of-life scores. J Clin Oncol 16:139-144

14. Verbeke GMG (2009) Linear mixed models for longitudinal data. Springer-Verlag, New York

15. Scott NW FP, Bottomley A (2008) EORTC QLQ-C30 reference values manual. EORTC quality of life group publications, Brussels, Belgium

16. Tribius S, Reemts E, Prosch C, Raguse M, Petersen C, Kruell A, Singer S, Bergelt C (2012) Global quality of life during the acute toxicity phase of multimodality treatment for patients with head and neck cancer: can we identify patients most at risk of profound quality of life decline? Oral Oncol 48:898-904

17. Abdel-Wahab M, Abitbol A, Lewin A, Troner M, Hamilton K, Markoe A (2005) Quality-of-life assessment after hyperfractionated radiation therapy and 5-fluorouracil, cisplatin, and paclitaxel (Taxol) in inoperable and/or unresectable head and neck squamous cell carcinoma. Am J Clin Oncol 28:359-366

18. Forastiere AA, Burtness BA (2007) Epidermal growth factor receptor inhibition in head and neck cancer-more insights, but more questions. J Clin Oncol 25:2152-2155

19. Hitt R, Grau JJ, Lopez-Pousa A, Berrocal A, Garcia-Giron C, Irigoyen A, Sastre J, Martinez-Trufero J, Brandariz Castelo JA, Verger E, Cruz-Hernandez JJ, Spanish H, Neck Cancer Cooperative Group (2014) A randomized phase III trial comparing induction chemotherapy followed by chemoradiotherapy versus chemoradiotherapy alone as treatment of unresectable head and neck cancer. Ann Oncol 25:216-225

20. Haddad R, O'Neill A, Rabinowits G, Tishler R, Khuri F, Adkins D, Clark J, Sarlis N, Lorch J, Beitler JJ, Limaye S, Riley S, Posner M (2013) Induction chemotherapy followed by concurrent chemoradiotherapy (sequential chemoradiotherapy) versus concurrent chemoradiotherapy alone in locally advanced head and neck cancer (PARADIGM): a randomised phase 3 trial. Lancet Oncol 14:257264

21. Cohen EEW, Karrison TG, Kocherginsky M, Mueller J, Egan R, Huang CH, Brockstein BE, Agulnik MB, Mittal BB, Yunus F, Samant S, Raez LE, Mehra R, Kumar P, Ondrey F, Marchand P, Braegas B, Seiwert TY, Villaflor VM, Haraf DJ, Vokes EE (2014) Phase III randomized trial of induction chemotherapy in patients with N2 or N3 locally advanced head and neck cancer. Journal of Clinical Oncology 32:2735-273+

22. Kaanders JH, van der Kogel AJ, Ang KK (1999) Altered fractionation: limited by mucosal reactions? Radiother Oncol 50:247-260 